\title{
Lung health for all Canadians?
}

$\mathrm{R}$ eceiving my first personal e-mail message the other day was something of a landmath.

Not that I an unreceptive to the advantages of the information highway, in one form or another: far from it. It's just that I have become so used to dialling up. and after several tries

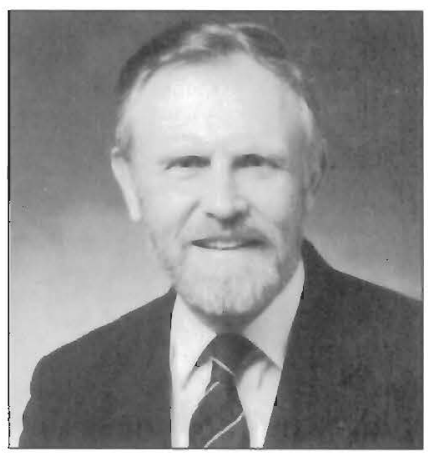
(LINE BUSY it silys), getling a long list of administrative messages, whose only interest comes when you get to push the "purge' command, appropriate when you consider their constipated contents.

Anyway, there it was; a personal message from my long time pediatric colleague, Angus McMillan, champion yachtsman and champion of Aboriginal health rights. Over many years it has been his habil, and thall of his wife Bev, to spend time in northern Ontario, working with the Cree community. His message: "The infant death rate due to pneumonia and bronchitis in Aboriginalis is 2.4/1000 live births, 12 times that in the tolal Canadian population."

In the hope and expectiltion that I an not the only Canadian respirologist not to know this statistic, I asked for more infornlation. which was rapidly forthcoming. A recent review by Fraser-Lee and Hessel (1) has pointed out that there is ample cvidence thall acute respiratory infections pose a great risk to Natives in Canada, with a mortality that is three to 2 I times that of the general population, and a morbidity rate from pneumonia that ranges from three to 18 times higher. The authors dispel the notion that socionvirommental factors may lead to a lower threshold for admission to hospital. Risk lactors alre identified as a high ratc of cigarette smoking in children and parents. bottle-feeding of infants, and possibly low birthwcight. crowded houscholds. environmental pollution, and obesity: however, research that might quimtily the independent effects of these lactors is lacking.

While one might see the solution to be improvenent in social and economic circumstances, Fraser-Lee and Hessel point to successful control progarans for acute respiratory infections in Nepal, Indonesial and Pakistan that have resulted in $50 \%$ reductions in morlality, in the absence of changes in social and economic circumstances. Important features of such control programs have been case management guidelines for local health workers, immunization for diphtheria, measles and pertussis and rish factor modification. Clearly these measures might be instituted in Native Canadian communities, but they would need 10 be accompanied by development of research strategies and priorities determined by Native people thenselves.

Although there is much information regarding respiratory infections, we lack data on other respiralory problems: it seens: very likely that asthma morbidity and mortality would be similarly greater. As respirologists we should be open to requests for help from our local and regional Native groups. The cost of measures to improve lung health in Native Canadians is likely to be modest, and the returns priceless.

\section{REFERENCE}

1. Fraser-Lee NJ. Hessel PA. Acute respinatory infections in the Canadian Nalive Indian population: al review. Can J Public Health 1994:85:197-200. 


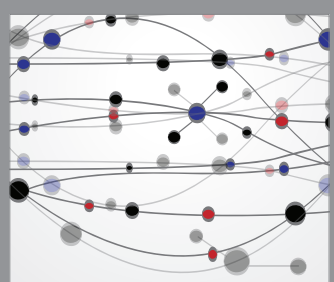

The Scientific World Journal
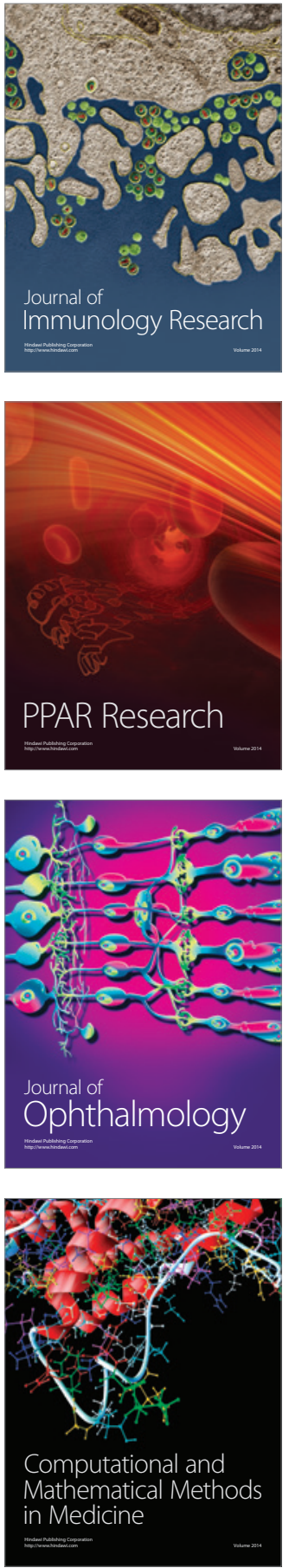

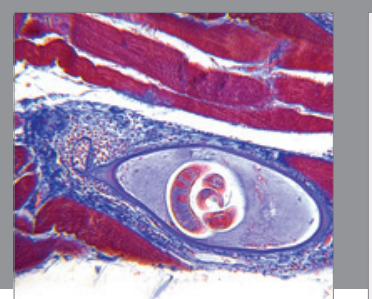

Gastroenterology Research and Practice

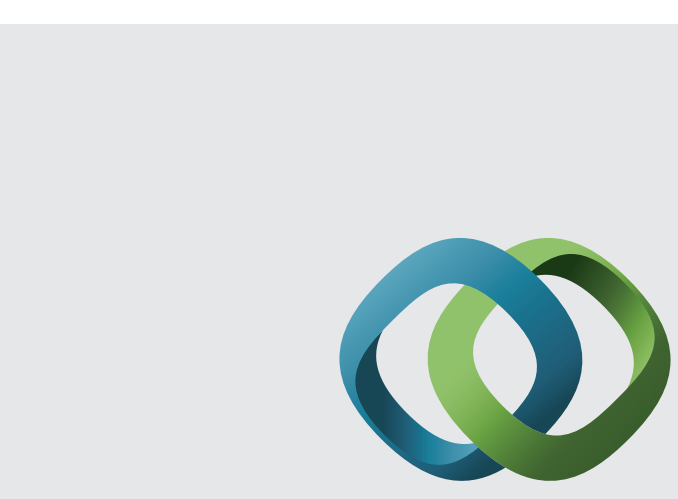

\section{Hindawi}

Submit your manuscripts at

http://www.hindawi.com
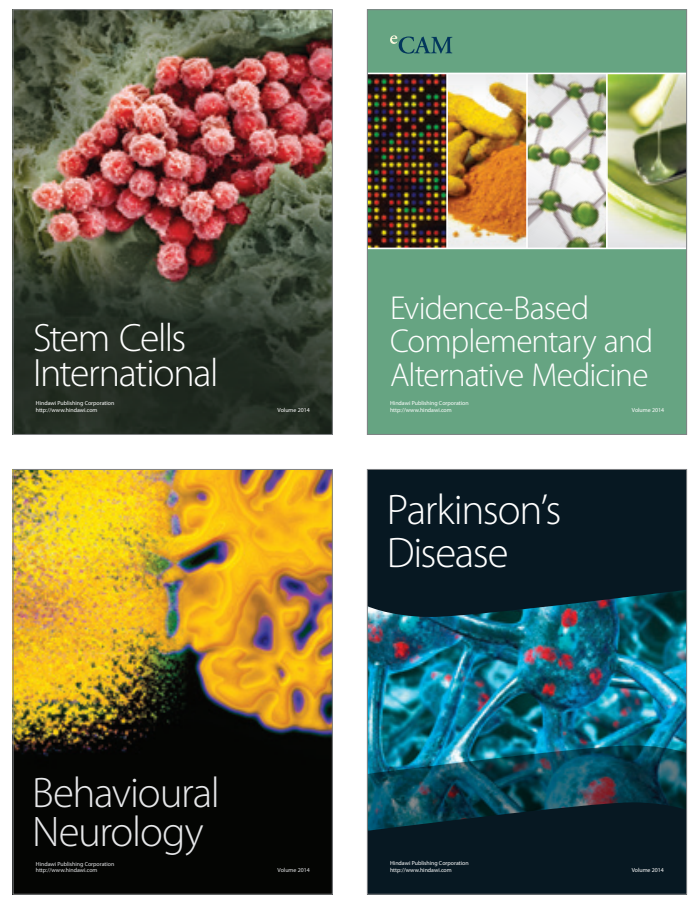
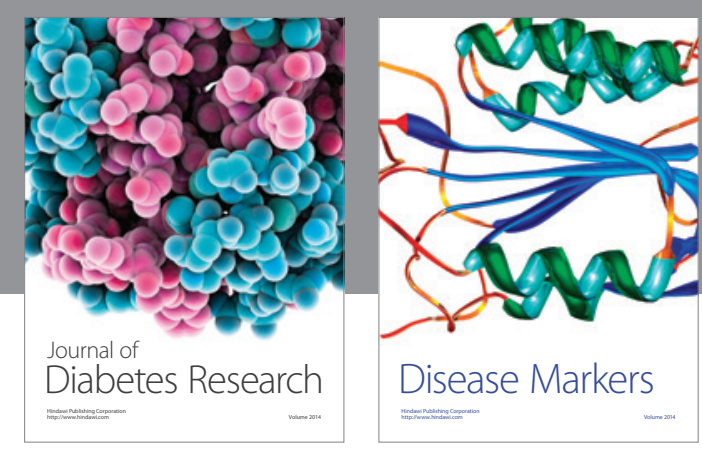

Disease Markers
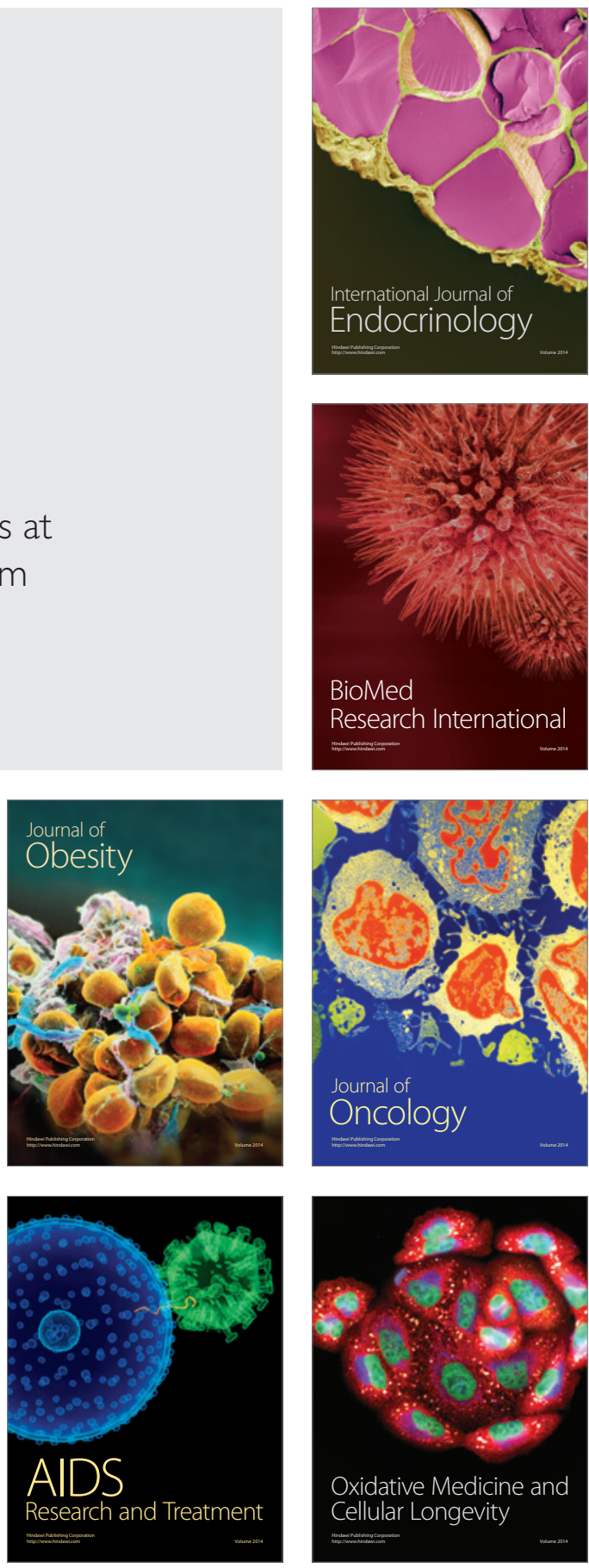